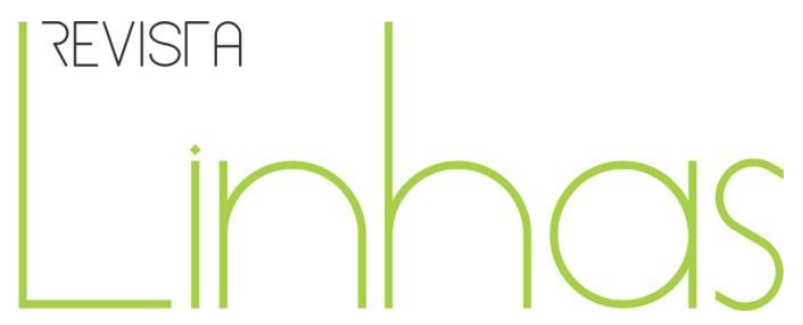

\title{
Atendimento Educacional Especializado para estudante com deficiência intelectual: os diferentes discursos dos professores especializados sobre o que e como ensinar
}

\begin{abstract}
Resumo
A crença na possibilidade de escolarizar indivíduos com deficiência intelectual é relativamente recente em nosso país, surge com o aparecimento das primeiras classes especiais nas escolas comuns, no início do Século 20, se generaliza a partir da década de 1970, com o advento da filosofia de integração escolar, e sofre alterações no final dos anos de 1990, com o advento da educação inclusiva. Na atualidade, o imperativo da escolarização de estudantes com deficiência intelectual nas escolas comuns traz razoáveis desafios aos professores que se questionam: o que e como ensinar esses alunos? O presente trabalho apresenta, ilustra e discute oito diferentes tendências curriculares encontradas em discursos de professores do Atendimento Educacional Especializado para estudantes com deficiência intelectual e que se referem a ênfases no ensino em: 1) Autonomia (atividades de vida diária), 2) Motivação (atividades lúdicas e de lazer), 3) Instrumentação (uso de recursos tecnológicos), 4) Currículo padrão (reforço do conteúdo acadêmico da classe comum), 5) Currículo adaptado (conteúdo acadêmico simplificado), 6) Prontidão ou preparação (ênfase em atividades psicomotoras), 7) Letramento e alfabetização (leitura e escrita) e, 8) Compensatório (treino em habilidades cognitivas superiores para o impedimento intelectual). Ao final, problematiza-se a existência dessas diferentes abordagens e a complexidade do conceito e da população dos estudantes enquadrados na condição de deficiência intelectual.
\end{abstract}

Palavras-chave: Educação Especial; Inclusão Escolar; Deficiência Intelectual; Atendimento Educacional Especializado; Professores Especializados.
Enicéia Gonçalves Mendes

Universidade Federal de São Carlos - UFSCar - SP/Brasil egmendes@ufscar.br

\section{Gabriela Tannús-Valadão}

Universidade Federal de São Carlos - UFSCar - SP/Brasil gabytannus@gmail.com

Josiane Beltrame Milanesi Universidade Federal de São Carlos - UFSCar - SP/Brasil milanesi.josiane@gmail.com

\section{Para citar este artigo:}

MENDES, Enicéia Gonçalves; TANNÚS-VALADÃO, Gabriela; MILANESI, Josiane Beltrame. Atendimento educacional especializado para estudante com deficiência intelectual: os diferentes discursos dos professores especializados sobre o que e como ensinar. Revista Linhas. Florianópolis, v. 17, n. 35, p. 45-67, set./dez. 2016. 


\title{
Specialized Educational Services for intellectual disabled student: the different teacher's speeches about what and how to teach
}

\begin{abstract}
The beliefs in the possibility to educate individuals with intellectual disabilities is relatively new in our country, appeared the first in special classes of public schools in the early 20th century, it generalizes from the 1970s, with the advent of philosophy integration and normalization, and changes in the late 1990s, with the principle of inclusive education. Today, the education of students with intellectual disabilities in regular school is imperative, this provides reasonable challenges, and teachers are asking themselves: what and how to teach these students? This paper presents, illustrates and discusses eight different curricular trends founded in teacher's speeches of specialized educational services for students with intellectual disabilities and refer to teach with emphases on 1) autonomy (activities of daily living), 2) motivation (leisure and recreational activities), 3) instrumentation (use of technological resources), 4) standard curriculum (strengthening of the academic content of the common classroom), 5) adapted curriculum (simplified academic content), 6) readiness or preparation (emphasis on psychomotor activities), 7) literacy (reading and writing) and 8) compensatory (training in cognitive skills higher for intellectual impairment). Finally, we discussed the existence of these different approaches and the complexity of the concept and the population of the students covered by the intellectual disability condition.
\end{abstract}

Keywords: Special Education; School Inclusion; Intellectual Disability; Specialized Educational Services; Specialized Teacher. 


\section{Introdução}

A preocupação em isolar para estudo a condição que hoje se denomina como DI surgiu no século XIX, com Esquirol, que observando a população institucionalizada em hospitais para os chamados alienados da razão, definiu o que ele denominou de "idiotia", e a partir da observação das características de pessoas institucionalizadas, com incapacidades acentuadas, estigmas físicos bem demarcados, e inadequações pessoais e sociais generalizadas, construiu as primeiras teorias sobre o assunto. Esquirol postulou três pressupostos básicos que passaram a ser continuamente reforçados nas definições posteriores de idiotia: a base orgânica, o déficit intelectual e a noção de incurabilidade (MENDES, 1995).

Ao longo de mais de quatro séculos de estudos, a condição de idiotia mudou de nome várias vezes (oligofrenia, retardo mental, deficiência mental); mudaram as definições, desafiaram-se as antigas teorias de modo que uma compreensão mais abrangente do conceito atual de deficiência intelectual (DI) requer conhecimento sobre essa história. Mendes (1995) divide a história do estudo científico da DI em três momentos de transformações teóricas, considerando o estudo dos determinantes das características, das definições científicas e das abordagens educacionais relacionadas a esta condição.

O primeiro momento compreende desde o nascimento do estudo científico sistemático, no início do século XIX, até o início do século XX, e foi caracterizado pela crença na hereditariedade, na irreversibilidade e o sentimento de ameaça social que representava a condição na época. Essas concepções explicam a marginalização, reprovação social, confinamento em instituições, esterilizações e outros mecanismos visando o controle social da idiotia. Na perspectiva teórica, a categoria genérica denominada como "idiotia" se subdividia nas subcategorias de "idiotia" e "imbecilidade". No âmbito educacional destacaram-se a pedagogia de Itard, Seguin e Montessori, que enfatizavam a necessidade do treino sensorial e uso do movimento, visando restaurar a integridade neurológica destes indivíduos, com o ensino especial desenvolvido em bases tutoriais e em instituições residenciais (PESSOTTI, 1984).

O segundo momento dessa história começa no século XX, indo até seus meados, e é caracterizado pela expansão do objeto de estudo da área. A incapacidade de atender às 
exigências acadêmicas da escola pública, recém instituída em muitos países, resultou na criação de classes especiais para atender esta população. Binet atribuiu um déficit intelectual de grau leve a esta incapacidade escolar, denominando-a como "debilidade mental", associando tal condição à idiotia e à imbecilidade, já consideradas como graus de desvio intelectual. Nessa fase, o desenvolvimento da tecnologia da testagem mental proporcionaria influências definitivas sobre os caminhos que a teoria da idiotia iria assumir, principalmente pela possibilidade de tomar decisões legais e educacionais, com base na aplicação dos testes intelectuais. Nesse momento, o construto científico de idiotia aparece como uma representação teórica mais arbitrária ou simbólica do que as definições do período anterior, agora claramente baseado em critérios socioculturais. No âmbito educacional, observa-se a proliferação das instituições residenciais, das escolas especiais e das classes especiais nas escolas públicas, e de divergências quanto às atividades curriculares mais indicadas: se habilidades acadêmicas ou habilidades práticas para a vida diária.

O terceiro momento teve início na segunda metade do século XX, caracterizado por uma intensificação deste estudo e por mudanças bastante dinâmicas na teoria e prática relacionadas à idiotia. A partir da década de 1930 a 1940, observa-se um maior questionamento dos pressupostos de organicidade patológica e da incurabilidade. A categoria genérica da idiotia passa a ser denominada como retardo mental, e nas definições aparece a inclusão de um, ainda vago, conceito de incompetência social, indicando descontentamento crescente em relação à utilização do critério psicométrico unitário, baseado no Quociente de Inteligência - QI, para embasar as decisões educacionais. Nessa época, a condição perde a referência à etiologia orgânica e incurabilidade, e para marcar essa mudança é assumida uma nova terminologia sendo definidas novas subcategorias: deficiência mental limítrofe, leve, moderada, severa e profunda.

A partir da década de 60 se observa uma evolução maior no ensino especial, com a representação de duas correntes da Psicologia que passam a se dedicar mais profundamente a este estudo. Da abordagem comportamental começam a derivar vários procedimentos para o ensino de habilidades mais práticas para indivíduos com prejuízos mais demarcados. Da abordagem cognitivista-desenvolvimentalista são derivados 
procedimentos para a remediação de problemas e ensino relacionados às habilidades acadêmicas. Na perspectiva do sistema educacional, os diferentes graus de deficiência ou retardo mental começam a ser classificados como "educáveis", "treináveis" e "dependentes" ou "custodiais", relacionados a expectativas de aprendizagem dessas diferentes subpopulações que compõem a categoria genérica. Em relação à qualidade dos serviços, surge também neste período, um escrutínio maior sobre a efetividade das classes especiais, escolas especiais e instituições residenciais, e emerge a filosofia de normalização e integração, com a defesa de que a escolarização dessas pessoas deve acontecer em ambientes educacionais com o mínimo de restrição possível, e que se aproximassem ao máximo dos ambientes naturais.

A partir da década de 1950, as definições começam a se apoiar cada vez mais nos manuais internacionais de classificação das doenças, com predomínio dos sistemas de classificação da Associação Americana sobre Deficiências Intelectuais e de Desenvolvimento (AAIDD ${ }^{1}$ ) que tem atuado de forma mais significativa nas definições socioeducaionais". Atualmente, a DI é definida como uma incapacidade "caracterizada por limitações significativas no funcionamento intelectual e no comportamento adaptativo, como expresso nas habilidades práticas, sociais e conceituais, originando-se antes dos dezoito anos de idade" (LUCKASSON et al., 2002, p. 08). Em 2010, a AAIDD adotou a nomenclatura deficiência intelectual atendendo a uma reinvindicação das pessoas enquadradas nessa condição e pelo fato do termo ser cientificamente mais preciso, menos ofensivo e demonstrar mais respeito e dignidade para com as pessoas enquadradas nessa condição.

No Brasil, os documentos oficiais brasileiros têm adotado a terminologia, a definição e as respectivas recomendações para a identificação de pessoas com DI da AAIDD (VELTRONE, 2011). Para avaliação da DI, a definição de 2010 da AIDD propõe que esta deve ter como propósito o diagnóstico, classificação e definição dos apoios e do sistema de suportes. Assim sendo, o diagnóstico tem, também, a função de eleger

\footnotetext{
${ }^{1}$ Antiga Associação Americana de Retardo Mental (AAMR - American Association on Mental Retardation), atual Associação Americana sobre Deficiências Intelectuais e de Desenvolvimento (AAIDD - American Association on Intellectual and Developmental Disabilities).

${ }^{2}$ Bem como nas definições trazidas nos documentos de organismos internacionais como a OMS.
} 
serviços, benefícios e proteções legais e deve levar em consideração a diversidade cultural, linguística, etc.

Analisando as mudanças no estudo da DI ao longo do tempo, MENDES (1995) pontua que o termo é um construto científico, uma invenção, ou um artifício linguístico que tem permitido classificar ou categorizar eventos de acordo com normas particulares de grupos; normas estas que são circunstanciais e que têm variado ao longo do tempo. Assim, na atualidade, o termo é um amplo guarda-chuva que abriga indivíduos que pelos mais variados motivos não conseguem atender as exigências sociais, e que por razões pragmáticas têm sido agrupados arbitrariamente numa mesma condição. Segundo a autora, em decorrência disto, o campo se defronta com problemas aparentemente insolúveis e com uma compreensão ainda incompleta do que é a DI, e que induzem a divergências teóricas e dificuldades para se estabelecer conclusões sobre qual é a melhor forma de educar esses indivíduos.

Assim, a deficiência intelectual engloba pessoas com características peculiares muito diversas que são reunidas numa mesma categoria, tomando como base um suposto funcionamento intelectual diminuído.

Até o advento da filosofia de inclusão escolar, a preocupação de como educar esses alunos era da Educação Especial organizada enquanto um sistema paralelo, que nem sempre desenvolveu uma vocação de escolarizá-los, se restringindo, muitas vezes, a cuidar, reabilitar ou, no mínimo, a oferecer propostas curriculares alternativas. Com o ingresso desse alunado na classe comum, novas questões emergem sobre como os professores devem ensinar respondendo as especificidades desses alunos nas salas comuns e no Atendimento Educacional Especializado (AEE).

Pletsch (2009), investigando as práticas curriculares em duas escolas no município do Rio de Janeiro, conclui que os resultados revelaram não só as contradições mas, acima de tudo, a complexidade do processo de inclusão vivido pelas escolas, particularmente no âmbito das práticas curriculares dirigidas para o processo de ensino-aprendizagem dos alunos com DI.

Há que se pontuar que as questões envolvendo o currículo escolar são complexas e vão muito além dos alunos considerados com deficiência. Há que se assinalar, também, 
que a formação de professores possui dilemas pertinentes e que as habilidades cognitivas são altamente valorizadas podendo, muitas vezes, levar a uma compreensão de que alunos com DI seriam inelegíveis para a aprendizagem de conteúdos convencionais.

Segundo estimativas do DSM-IV (AMERICAN PSYCHIATRIC ASSOCIANTION, 1994) os indivíduos com deficiência intelectual leve compõem cerca de $85 \%$ dessa população, enquanto que a proporção de indivíduos com DI de graus moderado, severo e profundo respondam, respectivamente, por $10 \%, 3 \%$ e $2 \%$ da população geral de indivíduos com DI (AMERICAN PSYCHIATRIC ASSOCIANTION, 1994).

O Instituto Brasileiro de Geografia e Estatística (IBGE) "estipulou, no ano de 2000, a existência de 24,5 milhões de brasileiros com deficiência, e estima-se que 50\% deles tenham algum grau de DI" (SCHWARTZMAN, 2013, p. 251). O

QUADRO 1 apresenta a proporção de matrículas dos alunos com DI no ensino regular, na Educação Especial e na Educação de Jovens e Adultos, englobando as esferas Federal, Estadual, Municipal e privada, considerando os percentuais daqueles com DI em comparação com todas as demais deficiências, transtornos globais do desenvolvimento e altas habilidades/superdotação, no ano de 2014.

QUADRO 1 - Proporção dos alunos com DI em comparação com o PAEE ${ }^{3}$ matriculados por regiões brasileiras e em todo o país

\begin{tabular}{|l|l|l|l|l|l|}
\hline Brasil & Sul & Sudeste & $\begin{array}{l}\text { Centro } \\
\text { Oeste }\end{array}$ & Nordeste & Norte \\
\hline $69,7 \%$ & $78,4 \%$ & $69,9 \%$ & $70,5 \%$ & $64,7 \%$ & $62,2 \%$ \\
\hline
\end{tabular}

Fonte: Microdados do censo escolar BRASIL/INEP (2014).

Assim, observa-se que, de fato, os alunos com DI concentram o maior número de matrículas e somam, ao todo, cerca de 70\% de todo o contingente de alunos PAEE. Além de ser o maior contingente do alunado, o fato do déficit ser de natureza cognitiva, faz com que esses alunos - que são o PAEE, sejam os maiores causadores de dúvidas e desafios no espaço educacional.

\footnotetext{
${ }^{3}$ Atualmente compõe o Público-alvo da Educação Especial (PAEE) as pessoas com deficiência (de ordem física, intelectual ou sensorial), com transtornos globais do desenvolvimento e com altas habilidades/superdotação.
} 
Ao analisar as orientações oficiais para o ensino de indivíduos com DI na década de 1990, Ferreira (1990) apontou uma contradição, pois os mesmos documentos que enfatizam igualdade curricular em relação aos programas regulares, frequentemente ignoravam conteúdos acadêmicos e enfatizavam habilidades básicas de vida diária, produzindo um nivelamento rebaixado das necessidades educacionais especiais dos estudantes considerados educáveis, igualando-os aos chamados treináveis e, consequentemente, reforçando preconceitos e estereótipos e favorecendo uma imagem ainda mais deteriorada da condição genérica da DI.

Ao revisar os estudos nacionais sobre o ensino especial de estudantes com DI no Brasil até a década de 1990, em classes especiais nas escolas públicas, Mendes (1995) concluiu que:

1) Havia generalizações incorretas, a partir do rótulo de DI nas prescrições de como deveria ser a educação dessa população, como se fosse um conceito monolítico, e seus indivíduos igualmente limitados;

2) Os processos de ensino se concentravam na recuperação ou remediação de supostas etapas ou habilidades que faltariam ao aluno com deficiência intelectual;

3) Negligenciava-se o ensino de assuntos acadêmicos e priorizava-se o ensino de supostos pré-requisitos para tais habilidades;

4) Adotavam-se currículos "especiais" tipicamente remediativos que pressupunham que os problemas estivessem centrados no indivíduo, cuja incapacidade escolar estaria relacionada a processos cognitivos subjacentes;

5) Adotava-se metodologia em que praticamente se assumia a infantilização do estudante, a partir de um raciocínio equivocado que equacionava o conceito de "idade mental" inferior com ensino de habilidades típicas do nível pré-escolar, para adquirir alguma espécie de "prontidão" para a alfabetização, e com estratégias que se resumiam a treinar os alunos em atividades supostamente preparatórias, com ênfase na repetição.

E assim, sob o termo "Educação Especial", encontram-se no Brasil, nas décadas de 1980 e 1990, vários procedimentos para, primeiramente, rotular indivíduos, principalmente aqueles indesejados pela escola comum, tratando-os como crianças préescolares, e oferecendo-lhes uma educação que poderia lhes acrescentar um duplo ônus, 
o rótulo e o estigma da condição, além da minimização das suas potencialidades através de uma educação de qualidade inferior (FERREIRA, 1989).

No final de década de 1990, o país assiste à entrada do debate sobre inclusão escolar, educação inclusiva, e a partir daí surgem novos dispositivos legais, e a orientação da política passa a ser de garantir a escolarização da população alvo da Educação Especial nas classes comuns das escolas regulares, com o apoio do AEE. E como estão sendo ensinados no presente esses estudantes com DI que estão sendo escolarizados em escolas comuns?

O presente estudo foi delineado para descrever e analisar como esses alunos têm sido ensinados no contexto do AEE por professores de Salas de Recursos Multifuncionais (SRM). A opção de investigar o ensino nesse contexto, e não da classe comum, se deve ao interesse em precisar o que os professores, supostamente especializados, fazem de “especial” ou diferente, no ensino dessa população com DI, no contexto das SRM.

\section{Metodologia}

O presente estudo foi realizado pelos pesquisadores do Observatório Nacional de Educação Especial (Oneesp) cujo foco é a produção de estudos integrados sobre as políticas e práticas voltadas para a questão da inclusão escolar na realidade brasileira. 0 estudo inaugural do Oneesp, desenvolvido em rede, teve como objetivo a avaliação em âmbito nacional do programa de implantação de SRM, promovido pela Secretaria de Educação Continuada Alfabetização, Diversidade e Inclusão (SECADI/MEC), a qual desde 2005 vem apoiando a criação desse serviço de AEE para o público-alvo da Educação Especial em todo o país.

O projeto foi proposto inicialmente por 25 pesquisadores oriundos de 16 estados brasileiros (Alagoas, Amapá, Bahia, Espírito Santo, Goiás, Maranhão, Mato Grosso do Sul, Minas Gerais, Rio de Janeiro, Rio Grande do Norte, Rondônia, São Paulo, Santa Catarina, Sergipe, Paraíba e Paraná), representantes de 22 universidades e de 18 programas de pósgraduação. Os estudos foram conduzidos em 56 municípios através de encontros sistemáticos com os professores de SRM, para realização de grupos focais sobre os três eixos temáticos de interesse do projeto: a avaliação do aluno, a formação dos 
professores e a organização e funcionamento das SRM. A coleta de dados foi conduzida ao longo de quatro anos (2010-2014), sendo que os encontros com os professores foram gravados e as falas foram transcritas.

Para o presente artigo foram selecionados para análise parte dos dados do eixo organização e funcionamento das SRM, sendo 65 documentos, equivalente a 69\% do total coletado, e contou com a participação de 170 professores de AEE. Cada um desses documentos são textos contendo as transcrições de sessões de entrevistas com grupo focais com os professores do AEE de 22 municípios de 10 estados, a saber, Espírito Santo (7), São Paulo (4), Rio de Janeiro (3), Pará (2), Goiás (1), Amazonas (1), Mato Grosso do Sul (1), Bahia (1), Paraná (1), e Rondônia (1).

O conteúdo dos textos foi submetido à análise usando o software Atlas-Ti, sendo que, depois de tratados, o corpus de dados foi baseado na seleção preliminar de 370 excertos (quotations) provenientes de sete categorias (codes) sendo elas: AEE para DI; AEE para PAEE; Alunos com DI; Atividades realizadas com alunos com DI; Função da escolarização; Função do AEE; Objetivo do AEE para DI. Após essa seleção, foi retirada uma lista contendo esses 370 excertos que foram lidos na íntegra visando avaliar se eles abordavam de fato o tema de interesse do estudo, ou seja, a descrição do que e de como, eles, os professores especializados, ensinam alunos com DI na SRM. Após essa análise, e o descarte dos excertos que não continham as informações de interesse, o corpus de dados ficou restrito a 252 excertos. A seguir, procedeu-se o trabalho de síntese que envolveu a identificação de famílias de categorias, que foram denominadas como tendências curriculares encontradas nos discursos de professores do AEE sobre o ensino para estudantes com DI. 


\section{Resultados}

A síntese da análise dos dados resultou na identificação de oito diferentes tendências curriculares encontradas em discursos de professores do AEE para estudantes PAEE e que se referem a ênfases dadas no ensino de diferentes conteúdos, a saber:

1) Promoção da autonomia (Aut) - Quando os professores dizem enfatizar, ou priorizar o desenvolvimento de autonomia e, para isso, referem que ensinam habilidades práticas de autocuidado (por exemplo, lavar as mãos, comer sozinho, etc.), ou fazem referência à necessidade de um currículo funcional para ensinar habilidades práticas que possam ser aplicadas no dia a dia do aluno com DI, ao desenvolvimento de habilidades de socialização;

2) Promoção da motivação (Mot) - Quando os professores dizem enfatizar, ou priorizar o desenvolvimento da motivação do aluno, alegando necessidade de aumentar a autoestima e o engajamento, e assim justificam o uso de atividades lúdicas e recreativas com seus alunos com DI;

3) Treino instrumental (Instr) - Quando os professores dizem enfatizar, ou priorizar o ensino do uso de recursos tecnológicos em si sem referência aos objetivos pedagógicos dos mesmos, e seus relatos se referem, por exemplo, ao ensino do uso do computador, navegação na internet, uso de dispositivos de acesso ao computador (mouses e teclados adaptados, telas sensíveis ao toque, etc.), de softwares pedagógicos ou específicos de acessibilidade para estudantes com deficiência (por exemplo, leitores de texto, de ampliação, de tradução em libras, de tecnologia assistiva, de comunicação alternativa), ou de jogos adaptados ou pedagógicos;

4) Ensino de currículo padrão (CP) - Quando os professores dizem enfatizar, ou priorizar o ensino do conteúdo padrão da classe comum e fazem referências, por exemplo, às matérias do currículo tradicional (português, matemática, artes, ciências, etc.), evidenciando oferta de reforço escolar para promover acesso ao currículo padrão.

5) Ensino de currículo adaptado (CA) - Quando os professores dizem enfatizar, ou priorizar o ensino do currículo com adequações, adaptações ou ajustes de conteúdo (redução ou simplificação), nas atividades (como, por exemplo, simplificação), com recursos pedagógicos diferenciados ou mudanças de estratégias de ensino; 
6) Treino de prontidão ou preparação (PP) - Quando os professores dizem enfatizar, ou priorizar o ensino de habilidades que, supostamente, irão preparar o aluno para a alfabetização e, por isso, utilizam conteúdo curricular da Educação Infantil, com tarefas, por exemplo, psicomotoras especificas (recorte, pintura, colagem) para preparar para a escrita, ou de discriminação audiovisual para preparar para a alfabetização, etc.

7) Alfabetização e letramento (Let) - Quando os professores dizem enfatizar, ou priorizar atividades de letramento e alfabetização com foco específico na aquisição da leitura e/ou da escrita.

8) Treino compensatório (Comp) - Quando os professores dizem enfatizar, ou priorizar atividades que visem o treino de habilidades, supostamente deficitárias, nos alunos com DI, e que visem compensar a limitação intelectual, e recorrem a tarefas cognitivas, motoras, de atenção e concentração, de discriminação, raciocínio lógico, ou quando reportam genericamente ao treino em habilidades cognitivas superiores.

Cabe destacar que essas tendências não aparecem isoladas nos discursos dos professores, pois que muitas vezes eles citam várias dessas tendências, indicando muitas vezes que os professores têm uma concepção multifacetada de como deve ser o AEE e que no caso dos alunos com DI, o AEE objetivo deve ser talhado individualmente de acordo com as necessidades educacionais particulares dos alunos. A seguir, cada uma dessas tendências será ilustrada e discutida, destacando que, para isso, foram selecionadas ou recortadas falas para ilustrar mais didaticamente cada uma das categorias isoladamente.

\section{Atendimento Educacional Especializado com Foco Motivacional}

A ênfase nos aspectos motivacionais dos estudantes com DI está, em alguma medida, representada na proposta educacional de Maria Montessori, desde o Século XIX, que com seu método visava desenvolver comportamentos mais espontâneos. Ela propunha ambientes que favorecessem a liberdade de ação para garantir a motivação do aluno e o autoensino, e propunha reforçar a tendência natural à exploração do ambiente (MENDES, 1995). 
A tendência curricular com foco motivacional apareceu, também, com frequência, nos discursos de alguns professores especializados que defendem a necessidade das atividades serem prazerosas para os alunos com DI. Para isso, eles propõem atividades lúdicas, nem sempre com objetivos curriculares definidos, a não ser o de favorecer o engajamento, melhorar a autoestima, proporcionar atividades bem-sucedidas, ou mesmo para evitar cansaço, insucessos e frustação.

A função do AEE, eu e a professora trabalhamos até com melhoria da autoestima das crianças na nossa sala. Uma vez a família chegou: "olha esse menino aí, o pai dele é um drogado, ele não aprende nada e está abaixo da linha do zero, eu não sei o que vocês vão fazer com ele, mas está aqui". O menino ficou com tanta vergonha que quase não levantou a cabeça. Para melhorar a autoestima dele, mostrar que ele sabia muito e que ele tinha muito a nos ensinar, a professora ficava o tempo todo segurando na mão dele, de um lado e eu do outro. E para os que vão chegando, a gente está sempre com esse papel de melhorar a autoestima dos meninos, é um papel que eu vejo fundamental na nossa função.

O ensino comum tem mais a preocupação com a escolarização em si, que a criança tem que ler e saber a matemática e o AEE é muito mais além. A gente faz o papel de professor, assistente social, psicólogo, da terapeuta e muito mais, o nosso papel vai muito mais além da escolarização. $\mathrm{Na}$ verdade, nem foco tanto da escolarização, do ensinar a ler e a escrever, pois muitos enxergam que nós não somos reforço e essa não é a função do AEE, o trabalho vai muito mais além disso.

Eu acho que para eles o momento mais gratificante do dia é quando eles vão para a nossa sala, pois lá eles têm inúmeras possibilidades de várias atividades e de estarem desenvolvendo o potencial deles. "Tia, eu não quero mais escrever, não, eu estou cansado". Então vamos brincar um pouquinho com o jogo.

\section{Atendimento Educacional Especializado com Foco Compensatório}

Nessa abordagem, a DI é concebida como um impedimento no processamento de informações do indivíduo, o que seria a causa primária dos déficits no comportamento observável e, por isso, essa abordagem remediativa ou compensatória direciona o objetivo da intervenção no sentido de superar ou fortalecer estas habilidades subjacentes específicas. A abordagem também é referida como de "treino no processo", uma vez que ela não visa treinar para tarefas específicas (por exemplo, de leitura, escrita, cálculo, etc.), 
mas sim para as supostas habilidades envolvidas no processo de desempenhar determinada tarefa (por exemplo, atenção, concentração, raciocínio lógico, discriminação, etc.), na crença de que trabalhando o processo se obtém melhora no comportamento observável e a prevenção quanto a novos déficits (MENDES, 1995). Em certa medida, a proposta de ensino especial com foco remediativo, ou compensatório, ainda se faz presente no discurso de professores especializados sobre como estudantes com DI devem ser ensinados. Os excertos descritos a seguir ilustram essa tendência.

No caso, a nossa função, seria assim, desenvolver as habilidades, conseguir que os alunos desenvolvam suas habilidades e a do ensino comum é pôr em prática. Aqui nós vamos dar a base, no caso se o aluno não consegue ter concentração, aí a gente trabalha jogos, o jogo da memória para que o aluno consiga se concentrar, com isso ele já tem uma base e quando ele chegar na sala do ensino comum ele vai conseguir desenvolver aquilo ali, ele vai conseguir se concentrar mais nas atividades.

No caso da deficiência intelectual ou paralisia cerebral, aí também tem a complementação de algumas atividades como jogos para desenvolver a memorização, a atenção dos alunos, só isso.

Direcionar ele a partir das habilidades que ele tem, para a visual memória, depois já passo a adaptar aprendizado, e o processo questão memória visual, a partir da questão da conceituação, de forma a chamar a atenção dele na questão do visual, do toque a partir do estímulo da dinâmica, assim tem várias que cada criança reage nas habilidades.

\section{Atendimento Educacional Especializado com Foco na prontidão ou Preparação}

A origem dessa tendência pode ser traçada no século XIX, com a proposta do método fisiológico de Seguin que, seguindo a escola francesa do sensorialismo, defendia atividades que envolviam, por exemplo, movimentos corporais, exploração pelo tato, coordenação manual para desenvolver habilidades, etc. Ele priorizava o treinamento no movimento em resposta a sinais táteis, visuais e auditivos que envolvessem habilidades de discriminação, classificação e operações lógicas. Preocupava-o a privação da experiência e ele enfatizava bastante a necessidade de favorecer as explorações e habilidades manuais do educando (MENDES, 1995). A partir daí, surgiram várias propostas pedagógicas para estudantes com DI baseadas em atividades psicomotoras. 
Embora com menor frequência, alguns relatos dos professores de AEE sugerem essa tendência de se priorizar o ensino de habilidades psicomotoras (como por exemplo, envolvendo equilíbrio corporal, esquema corporal, lateralidade, estruturação temporalespacial, etc.) que são por eles consideradas necessárias para a aquisição de aprendizagens relacionadas ao currículo padrão.

Aí se precisa trabalhar a atenção dela, coordenação motora vai trabalhando.

A criança chegou lá no primeiro ano, ela nem segurava no lápis, e aí foi trabalhado com ela, ela passou a segurar no lápis, a conseguir fazer uma coisa no caderno, e aí quando eu sentava para conversar com essa professora eu dizia assim: olha professora ele, essa criança avançou, né?

\section{Atendimento Educacional Especializado com Foco no Currículo Padrão e Reforço Escolar}

A tendência de se priorizar o currículo padrão da série ou ciclo que o estudante frequenta na classe comum apareceu nos relatos dos professores do $A E E$, mesmo que esses reconheçam que essa não é a prática indicada nos documentos orientadores do Ministério da Educação (MEC):

Vejo assim, o AEE como um trabalho que desenvolve a criança especial, é um complemento do ensino regular na questão da aprendizagem, até porque no começo teve muita cobrança do ensino regular, na aprendizagem e no desenvolvimento da aprendizagem do aluno, aquele aluno que tem limitações, possui muita dificuldade, muitos não conseguem acompanhar o desenvolvimento dos demais, então a gente sabe que não é o nosso papel estar ali reforçando o que é trabalhado na sala comum, mas muitas vezes eu vejo ou procuro ajudar eles para ver se conseguem avançar, a gente acaba fazendo até um reforço de certa forma. A questão da aprendizagem dos conteúdos no AEE é trabalhar para complementar com outras formas, formas diferenciadas.

Ele é mais o conteúdo, por que às vezes ele não pega na sala de aula, aí a professora retoma na sala de recursos. O que acontecia era muito isso.

Eu tinha um aluno de oitava série, os conteúdos eram muitos e o tempo de atendimento era pequeno, então acabava sendo mesmo retomar o conteúdo, especialmente de trabalhos, por que da sala de aula do dia a dia não dava, entendeu? 
Eu queria falar uma coisa, por mais que fale assim, a sala de recurso não é uma sala de reforço, às vezes, na questão de matemática, principalmente no oitavo e nono ano (inaudível) não tem como você não ajudar o professor no conteúdo do currículo. É porque eles precisam, eles têm dificuldade, eu diria assim que até o quinto ano eu não me prendo em currículo, mas o sexto em diante, principalmente...

\section{Atendimento Educacional Especializado com Foco no Currículo Adaptado}

No tocante à relação ente currículo da classe comum e do AEE, outra tendência que se percebe nos relatos dos professores é o entendimento de que a função desse último é de adequar, ajustar ou adequar o currículo padrão aos alunos com DI.

O objetivo com a deficiência intelectual, desse grupo que atendo que é assim: adequa o conteúdo no nível possível, utilizando o recurso adequado, trabalha alfabetização. (Eles têm) muita dificuldade na aprendizagem, então é mais adequação do currículo mesmo.

A função do AEE, porque também é assim, as adaptações, adequações, adequação de conteúdo, é material para que o aluno possa acompanhar, a sala de recurso, ela e a comum, da sala comum aproximar esse aluno o mais possível do conteúdo com as adaptações, com as adequações que a gente proporciona a ele, se a sala comum conseguir que ele tenha um avanço no conteúdo, e que ele adquira o que é feito na sala.

Adaptar o currículo para que eles possam ter acesso ao aprendizado como todos. A escola conta com a sala de recursos para dar suporte ao aprendizado dos alunos e professores especializados, desta forma, facilitando as adaptações necessárias no momento do estudo no regular.

Muitas vezes, essa adaptação curricular aparece como uma espécie de simplificação ou modificação do currículo comum, quando, por exemplo, os professores propõem atividades do currículo da Educação Infantil para estudantes que frequentam classes comuns de ensino fundamental. 


\section{Atendimento Educacional Especializado com Foco no Letramento e Alfabetização}

A questão de se o ensino para estudantes com DI deve ou não priorizar as atividades de alfabetização e letramento, é assunto controvertido. Algumas professoras manifestaram opiniões contrárias a esta prática, principalmente, alegando que a SRM não deve ser um serviço de reforço escolar. Por outro lado, outras professoras defendem o letramento e a alfabetização como principal objetivo da escola e do AEE como, por exemplo, nos relatos a seguir:

Só que a gente encontra formas de fazer com que isso se torne uma realidade de mostrar que a criança realmente está aprendendo a ler, está aprendendo a escrever, de que forma? Por exemplo, eu trabalho bastante no começo da alfabetização com o mesmo campo semântico, depois com frases geralmente de contos, que eu dou em sala de aula, e ele já dominava as palavras, já escrevia, eu dava a palavra toda desmontada e ele montava, para montar ele teve que ler, essa é uma pista.

$\mathrm{Na}$ sala de recursos, como que a gente tem feito, por exemplo, com a professora regente: no começo do bimestre, a gente vê tudo que vai ser trabalhado, português vai trabalhar isso, história isso e tal, então quando eu trabalho a questão da alfabetização com ele, porque ele não está alfabetizado e eu não posso desconsiderar isso, eu tento incluir, por exemplo, no meu trabalho, uma poesia que ela está trabalhando. É, tento incluir, se eu vou trabalhar com uma lista, é; ah, eu estou trabalhando com animais aquáticos, a professora está trabalhando.

Eu concordo com todas as colegas, a gente busca isso mesmo, é que a gente trabalha com o aluno na alfabetização, quando possível, aproximálo dos colegas da sala, a socialização e a independência, autonomia, porque como ela disse, mesmo se ele não se alfabetizar, ele vai ser um cidadão, e a gente sente que eles vão ser um cidadão atuante.

A SRM, ela ainda tem que ser um recurso onde a criança adquire a leitura e a escrita para poder caminhar na sala regular. Eu acredito nisso porque sem ler essa criança vai se perder, ou ela vai desistir porque se essa criança tem condições de aprender, se ela pode caminhar mais, evoluir no processo da aprendizagem dela, se não tiver esse empenho na SRM, só na sala regular gente, tchau, não vai, não vai caminhar. 


\section{Atendimento Educacional Especializado com Foco na Instrumentação ou}

\section{Recurso}

Possivelmente, a terminologia "salas de recursos multifuncionais" tenha induzido uma compreensão de AEE por parte dos professores especializados de que o foco do ensino nessas salas tenha que ser o uso dos recursos, como ilustram os excertos a seguir.

A sala tem que oferecer atividades diferenciadas como jogos, tudo envolvendo as habilidades e dificuldades do aluno, eu acredito que é isso que a sala de recursos oferece.

Formação de cidadão, mais autônomo no lúdico e no tecnológico.

A função da sala de recursos é trabalhar com outros recursos né, como o próprio nome já diz, que é o que a professora da sala regular não consegue trabalhar, que eu encontro a professora dos dois, do fundamental e do recursos, eu sei o quanto é difícil pra gente dar atenção especial para o aluno de sala de recursos, até mesmo porque não tem só um, e eu esse ano tenho quatro, ano passado tinha três, então a gente dá atenção sim pra (alguns) da comum, alguns minutos, então você adapta alguma coisa, não dá pra adaptar tudo, é difícil, agora nós contamos com a ajuda da cuidadora que a gente adapta e ela aplica né, ela dá um suporte muito bom pra gente, então a função da regular é essa, é aproximar o aluno da sala de recursos com o conteúdo o máximo possível, e a função da sala de recursos, eu vejo que é trabalhar com outros, de outras formas diferentes da sala comum, outros meios, outros recursos mesmo pra que ele consiga alcançar outros objetivos do AEE.

\section{Atendimento Educacional Especializado com Foco na Autonomia}

Mendes (1995) aponta que Binet e Simon, no início do Século XX, mostravam-se particularmente céticos em relação às possibilidades de melhorar as capacidades intelectuais dos estudantes com DI e, por isso, propunham que a Educação Especial deveria se concentrar no ensino de habilidades sociais práticas, tais como ler sinais de rua ou atender a instruções simples. Essa ênfase na aprendizagem pela experiência em atividades cotidianas de vida diária passou a ser a fórmula mais defendida para o descarte da educação sensorialista e psicomotora/muscular predominante até então. Tal tendência acompanhava o movimento pelo pragmatismo e criticava o intelectualismo observado na educação regular neste mesmo período histórico. Essa defesa do ensino em habilidades práticas relacionadas ao treino em atividades de vida diária e na socialização aparece 
também nos relatos dos professores que postulam um currículo visando a aquisição de hábitos de higiene pessoal, autocuidados em geral, mas principalmente as habilidades sociais e práticas cotidianas:

Quando eu ensino um comportamento social para o meu aluno, automaticamente estou favorecendo a sala de aula comum, porque nós temos aquele menino que de manhã é uma pessoa que bagunça na escola, mas quando vem à tarde, a gente acalma e põe ele na sala, é uma pessoa tranquila, faz tudo que a gente pede.

Acho que não é só a questão do aprender a ler em si, mas da aprendizagem que é uma coisa bem mais ampla, o objetivo da inclusão... esse aluno tem que estar inserido na sala regular para desenvolver não só leitura e a escrita, ou a aprendizagem dos conteúdos acadêmicos, mas também uma socialização do aluno e a sua convivência para o meio social é um dos principais objetivos da educação.

\section{Conclusões}

A população atualmente passível de ser enquadrada na condição de DI é extremamente diversificada, como também são muito diferenciadas suas potencialidades e necessidades educacionais especiais. Uma grande porcentagem de indivíduos, cerca de $80 \%$, apresentam dificuldades restritas que são, exclusivamente, na esfera acadêmica. Para esta clientela, poucas adaptações devem ser feitas em relação aos processos educacionais regulares. Um número bem mais reduzido desta população apresenta dificuldades desenvolvimentais generalizadas, que podem ir desde o nascimento até a vida adulta. Neste grupo, as necessidades educacionais, que geralmente não são atendidas pelos processos formais e informais de ensino, o ensino é mais diferenciado e eles requerem programas mais individualizados e objetivos que, em geral, fogem às tradicionais habilidades acadêmicas tradicionais enfatizadas nas escolas comuns.

No caso dos alunos com DI matriculados em escolas brasileiras é provável que a maioria apresente dificuldades restritas na esfera acadêmica, e que as escolas especiais concentrem mais as matrículas de alunos com mais prejuízos. Além disso, tendo em vista a fragilidade dos processos de identificação desses alunos e a baixa qualidade do ensino em nossas escolas, é possível questionar se essas dificuldades se devem a um déficit 
intelectual desses alunos ou a incapacidade das escolas de ensinar com qualidade seus alunos (VELTRONE, 2011).

Considerando o conjunto dos alunos com DI, a literatura indica que o "especial” do ensino que eles precisam abrange desde pequenas modificações em aspectos do ensino comum, até grandes modificações, uma vez que as necessidades educacionais especiais desta clientela são muito diversificadas. Estes recursos podem envolver o ambiente de aprendizagem, recursos humanos qualificados, abordagens pedagógicas diferenciadas, procedimentos de ensino diversificados, e adequações ou modificações curriculares que especifiquem o que ensinar e em que sequência, e como organizar os objetivos em níveis e serviços educacionais. A quantidade e qualidade de recursos variam, dependendo das necessidades do educando e das possibilidades oferecidas pelo sistema educacional.

Observamos que no discurso atual de professores do AEE diferentes tendências se apresentam fazendo emergir a questão de qual seria a mais indicada para a escolarização de indivíduos com deficiência intelectual.

A esse respeito, cabe indicar que as teorias sobre "o que" e "como ensinar" começaram a surgir no Século XIX e, ao longo da história, surgiram várias propostas curriculares, sendo que nunca houve consenso sobre a melhor abordagem, principalmente em função da diversidade da clientela que é atualmente enquadrada na categoria genérica. Assim, uma primeira resposta a essa questão decorre da complexidade do conceito de $\mathrm{DI}$, que indica que é praticamente impossível propor currículos de forma genérica, ou mesmo para as diferentes subcategorias, como se houvesse algum grau de homogeneidade nesta clientela.

Assim, essa diversidade de tendência, em parte, pode ser explicada pela complexidade do conceito e pelas diferentes teorias que surgiram ao longo da história, principalmente considerando-se o foco compensatório/remediativo, na autonomia, na motivação, na prontidão e na alfabetização. Entretanto, outras tendências parecem inovadoras no campo da escolarização de estudantes com deficiência intelectual, que são aquelas atreladas ao currículo (padrão ou adaptado) e a de instrumentação.

As tendências que priorizam o currículo padrão, seja tentando reforçar o currículo da classe comum, seja para pensar na necessidade de como adequar esse currículo para 
os alunos com deficiência intelectual, possivelmente são consequência da própria prática de inclusão escolar que obriga a enquadrar esse novo contingente de alunos na organização escolar vigente e, de certa forma, manter a função da escolarização igual para todos os alunos

Outra conclusão possível para explicar algumas variações, para além das tradicionais abordagens curriculares para o ensino de indivíduos com DI, parecem da própria (in)definição dos documentos orientadores do MEC sobre como deve ser o AEE para estudantes com DI. O Livro Saberes e práticas da Inclusão do MEC de 2006, por exemplo, recomenda que se avalie na SRM “[...] as habilidades básicas que permitem, de modo mais ou menos eficaz, que o aluno enfrente as demandas das diferentes etapas do fluxo da educação básica" (BRASIL, 2006, p. 62).

Esses discursos do MEC, de certa forma, reforçam essa tendência de se pensar que na SRM não se deve ter como objetivo trabalhar conteúdos curriculares, mas sim as “habilidades" necessárias para acessar o currículo. Enfim, parece que as orientações no sentido de complementação, de não funcionar como reforço escolar, e a indicação para o trabalho com "habilidades cognitivas superiores" não tem sido suficientes para embasar a compreensão dos professores sobre o que deve ser o AEE para estudantes com DI. Além disso, o foco dado nos documentos à importância dos recursos na sala, aliado à revolução que as tecnologias (assistivas, de informação e comunicação) têm promovido na atualidade também parece induzir uma compreensão, por parte dos professores especializados, de que esses recursos devem assumir a centralidade do AEE para alunos com DI.

Cabe destacar que não se pretende aqui culpar os professores especializados, que gentilmente compartilharam suas práticas conosco, pois as falas aqui ilustradas não retratam o conjunto do pensamento dos professores entrevistados, uma vez que suas narrativas foram selecionadas e recortadas intencionalmente para ressaltar as tendências identificadas. Entretanto, ainda que a prática de algum dos professores pudesse se identificar integralmente com uma ou outra tendência, e essa, porventura, pudesse ser questionada, há que se destacar a precariedade da política de formação de professores para a educação inclusiva, além das dificuldades nas atribuições e condições de trabalho do professor do AEE em SRM (MENDES, CIA, CABRAL, 2014). 
Espera-se, entretanto, que os resultados e conclusões aqui apontadas sirvam para que os professores reflitam sobre suas práticas e se elas indicam, de fato, o melhor caminho para a escolarização de alunos com DI. Adicionalmente, espera-se que elas permitam aprofundar o debate sobre de quem é, afinal, a responsabilidade pela alfabetização desses alunos, de como garantir o acesso ao currículo comum para que a função da escola seja a mesma para todos e, finalmente, sobre a necessidade de se pensar o processo de escolarização do PAEE integrando-se as propostas curriculares da classe comum e do AEE.

\section{Referências}

AMERICAN PSYCHIATRIC ASSOCIANTION. Diagnostic and statistical manual of mental disorders. 4. ed. Washington, CD: APA, 1994.

BRASIL. Ministério da Educação e Cultura. Secretaria de Educação Especial. Saberes e práticas da inclusão: avaliação para identificação das necessidades educacionais especiais. 2. ed. Brasília: MEC. Secretaria de Educação Especial, 2006. 92 p.

BRASIL. Ministério da Educação. Instituto Nacional de Estudos e Pesquisas Educacionais Anísio Teixeira. Microdados do censo escolar 2014. Disponível em: <http://portal.inep.gov.br/basica-levantamentos-acessar>. Acesso em: 27 jul. de 2015.

FERREIRA, Julio Romero. A Construção escolar da deficiência mental. 1989.168 f. Tese (Doutorado em Educação) - Universidade Estadual de Campinas, Campinas, 1989.

FERREIRA, Julio Romero. Produção científica em educação especial. Temas em Educação Especial. São Carlos: Universidade Federal de São Carlos, n. 2, p.97-100, 1990.

LUCKASSON, Ruth et al. Mental Retardation: definition, classification, and systems of support. Washington, DC: American Association on Mental Retardation, 2002. 
MENDES, Enicéia Gonçalves. Deficiência mental: a construção científica de um conceito e a realidade educacional. 1995. Tese (Doutorado em Psicologia) - Universidade de São Paulo, São Paulo, 1995.

MENDES, Enicéia Gonçalves; CIA, Fabiana; CABRAL, Leonardo Santos Amâncio. (Org.). Inclusão escolar e os desafios para a formação de professores em educação especial. 1 . ed. São Carlos: Marquezine \& Manzine, 2015. v. 3.530p.

PESSOTTI, Isaias. Deficiência mental da superstição à ciência. São Paulo: T.A. Queiroz Editor Ltda/ EDUSP, 1984.

PLETSCH, Márcia Denise. Repensando a inclusão escolar de pessoas com deficiência mental: diretrizes políticas, currículo e práticas pedagógicas. 2009. 254 f. Tese (Doutorado em Educação) - Faculdade de Educação, Universidade do Estado do Rio de Janeiro, Rio de Janeiro, 2009.

SCHWARTZMAN, José Salomão. Deficiência intelectual. Temas sobre desenvolvimento, São Paulo, v. 19, n. 107, p. 250-260, 2013.

VELTRONE, Aline Aparecida. Inclusão escolar do aluno com deficiência intelectual no estado de São Paulo: identificação e caracterização. 2011. 193 f. Tese (Mestrado em Educação Especial) - Universidade Federal de São Carlos, Programa de Pós-Graduação em Educação Especial , São Carlos, 2011. 